\title{
Period of adult activity and response to wood moisture content as major segregating factors in the coexistence of two conifer longhorn beetles, Callidiellum rufipenne and Semanotus bifasciatus (Coleoptera: Cerambycidae)
}

\author{
RYÛTARô IWATA, TAKAHISA MARO, YASUSHI YONEZAWA, Tôru YAHAGI and Yoshirô FUJIKAWA* \\ Department of Forest Science and Resources, College of Bioresource Sciences, Nihon University, Fujisawa 252-8510, Japan; \\ e-mail: iwata@brs.nihon-u.ac.jp
}

Key words. Cerambycidae, Callidiellum rufipenne, Semanotus bifasciatus, coexistence of species, resource partitioning, diel activity, wood moisture content, temperature, sunshine

\begin{abstract}
The cerambycid borers Callidiellum rufipenne (Motschulsky) and Semanotus bifasciatus (Motschulsky) infest coniferous $\operatorname{logs}$ in Japan, with the latter distributed in the north and at high altitudes, where both species occur sympatrically. Semanotus bifasciatus adults were active at low temperatures and very active after sunset, and less active but never inactive in the daytime, whereas $C$. rufipenne adults were usually active at high temperatures and almost only in the daytime. At an almost constant temperature, $C$. rufipenne adults were almost inactive at night, whereas $S$. bifasciatus adults showed only an obscure decline in activity in the morning. Of a horizontal log, the upper surface tended to be drier and lower surface wetter, and C. rufipenne larvae grew large if they were in the upper part of a $\log$, whereas $S$. bifasciatus larvae grew large if in the lower part. Thus, the coexistence of these two species can be ascribed to two major segregation factors: adult segregation based on temperature and sunshine, and larval segregation associated with the moisture content of the wood.
\end{abstract}

\section{INTRODUCTION}

Resource partitioning, or niche segregation, is an important aspect of ecology, and for wood-boring insects, it is of paramount importance, especially in crowded conditions, because their larval habitat is usually restricted to the wood in which they occur (Beaver, 1984). Despite a large number of species in the Cerambycidae, there are very few studies on the niche segregation in sympatric species [e.g. Hellrigl (1971) on Monochamus spp.], compared to Scolytidae, for which there are many studies (e.g. Paine et al., 1981; Rankin \& Borden, 1991).

Two cerambycid species (Cerambycinae: Callidiini), Callidiellum rufipenne (Motschulsky), which occurs in the Korean Peninsula, Sakhalin (Russia) and almost the whole of Japan (Niisato, 1992), and Semanotus bifasciatus (Motschulsky), in Japan (South Hokkaido, Honshu), the Korean Peninsula and China (Wu \& Jiang, 1986; Niisato, 1992), are secondary borers of Cryptomeria japonica D. Don (Taxodiaceae), Chamaecyparis obtusa Sieb. \& Zucc. (Cupressaceae) and Thujopsis dolabrata (L. fil.) Sieb. \& Zucc. (Cupressaceae) in Japan (Kojima \& Nakamura, 1986). Distribution of the latter species is limited to northern parts and high altitudes, where both species occur sympatrically. In Nagano Prefecture Ch. obtusa logs infested with $S$. bifasciatus are always also infested with C. rufipenne (Hori, 1970). The adult flight period of both species is early spring in Japan (Hori, 1970; Shibata, 1994), like in the other Semanotus species that occur in the temperate zones of the northern hemisphere (Wickman, 1968; Zhang et al., 1983; Kobayashi, 1984). These two species, thus, may provide a model for studying niche segregation in Cerambycidae.

After the first observation of the co-occurrence of both species at Yunokoya Lumberyard, Minakami, Gunma Prefecture, in Ch. obtusa and T. dolabrata logs in May 1989, observations

\footnotetext{
* Deceased in 1995.
}

were continued in this area until 1995 on the niche segregation of these two species.

\section{MATERIAL AND METHODS}

Field observations on the adult activity of $S$. bifasciatus were carried out in May 1990 at Takaragawa Field Research Station (FFPRI), Minakami, Gunma Prefecture, Japan (alt. 790 m) and at Yunokoya Lumberyard, Minakami (alt. 770 m). Further observations on the activities of adults of the two species were carried out in 1991-1992 at Yunokoya Lumberyard, Yamamoto Lumberyard (alt. $620 \mathrm{~m}$ ) and Tsunako (alt. $550 \mathrm{~m}$ ), Minakami, Gunma Prefecture. Air temperature, and numbers of individuals of both species active on, resting on, and emerging from logs were recorded.

Adult beetles of both species observed in the lumberyards in 1992 were captured, and brought into the laboratory, where the beetles were placed in two plastic containers $(31 \times 45 \times 24 \mathrm{~cm}$ high), and their diel activity observed. In the evening of May 19 1992 , ten males and five females of each of the two species were introduced into one of the plastic containers with $5 \mathrm{Cr}$. japonica logs. After about $20 \mathrm{~h}$, their behaviour was observed for $10-15 \mathrm{~min}$ at hourly intervals over the following $24 \mathrm{~h}$. Whether they were resting, walking, mounting, copulating or ovipositing was recorded. At each observation, the air temperature in the containers was recorded. During the period of observation the laboratory illumination was switched off from sunset to sunrise.

Adults of the two species were collected at Yunokoya Lumberyard early in May 1990, brought into the laboratory, and allowed to mate and copulate conspecifically in Petri dishes. Several pairs of both species were selected, released together into a container with a newly felled $T$. dolabrata $\log$ (about 8 $\mathrm{cm}$ in diameter and about $30 \mathrm{~cm}$ in length) and left to mate and oviposit on the log. Four months later, the bark of each log was 


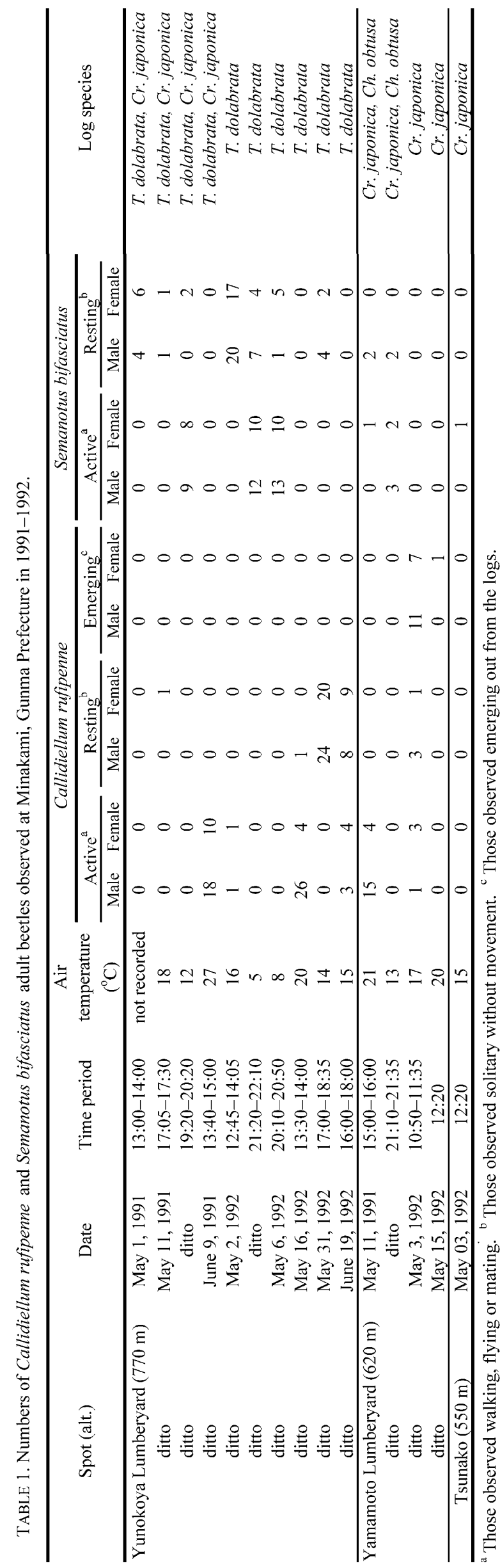

peeled off to expose the larval galleries. One log was selected as the best sample, and the area of all the galleries measured by applying paper to the xylem surface, tracing the galleries on the paper, photocopying the traces on high-quality paper, cutting out the traced gallery area, and measuring the area by weighing. We measured the sizes of the entrance holes, which were made by mature larvae of both species on the xylem surface in elliptic shape prior to forming pupal chambers. Then, after splitting the $\log$, the adult beetles were removed from their pupal chambers, identified, and then the depths of the pupal chambers and the positions of the larval entrance holes of the two species on the $\log$, namely whether on the upper, side or lower surface, were recorded.

To characterize the changes in and differences of the moisture contents of the upper, side and lower surfaces of horizontal logs of Cr. japonica and Ch. obtusa (45-118 cm long, 6.7-16.7 cm in diameter) they were subjected to the following experiment on 24 Sept. Five Cr. japonica logs and six Ch. obtusa logs were laid horizontally on the forest floor (University campus, Fujisawa, Japan; an airy, shady site under an evergreen-tree canopy with a thin leaf litter layer), and three $C r$. japonica logs and four Ch. obtusa logs were laid horizontally in containers in the laboratory. From 3 Oct. to 27 Jan., a portion $(1.5 \times 1.0 \times 0.5 \mathrm{~cm}$ thick) of wood was sampled from each of the three surfaces (upper, side and lower) of each log using a chisel and immediately weighed $(w)$. The sample chip was then oven-dried $\left(95-100^{\circ} \mathrm{C}\right)$ to obtain the dry weight $\left(w_{0}\right)$, and the moisture content calculated by using the following equation, which is widely used in wood science (Kollmann \& Côté, 1968): $M=\left\{\left(w-w_{0}\right) /\right.$ $\left.w_{0}\right\} \times 100 \%$.

\section{RESULTS AND DISCUSSION}

\section{Adult activity in lumberyards and the laboratory}

The behaviour of adult $S$. bifasciatus beetles observed in lumberyards in May 1990 (data not shown) indicated that they are active even at a low air temperature of $11.6^{\circ} \mathrm{C}$.

The numbers of individuals of both species recorded in 1991-1992 are summarized in Table 1. It demonstrates that $S$. bifasciatus adults were active at temperature of $5-20^{\circ} \mathrm{C}$ and very active after sunset, and less active but not inactive in the daytime, whereas $C$. rufipenne adults were usually active at temperature above $15^{\circ} \mathrm{C}$ and almost only in the daytime.

The results of the hourly observations in the laboratory of the activity of adults of both species are presented in Fig. 1. Starzyk (1968) presented a comparison of the daily adult activity of Gaurotes virginea (L.) (Cerambycidae: Lepturinae: Rhagiini) in natural and laboratory conditions and suggested that there is little difference between the two. This may validate our results from the laboratory experiments. At an almost constant temperature, C. rufipenne adults exhibited almost no activity between 22:00 and 8:00 and were found hiding under or between the logs. This is consistent with Yogo's (1954) statement that it is a typical diurnal species. On the other hand, $S$. bifasciatus adults showed only an obscure decline in activity before midday. Hori (1970) stated that S. bifasciatus adult beetles are nocturnal and active when the temperature is above $5^{\circ} \mathrm{C}$ between sunset and sunrise. The weak daytime activity, exhibited by S. bifasciatus, was also recorded for the congeneric species, S. japonicus (Sugiyama et al., 1991, 1992). This difference in the activity pattern of the adults is the most important factor that segregates the adult niches of the two species. In both species, reproductive behaviour (mounting, copulating and ovipositing) generally occurred whenever the beetles were active. 


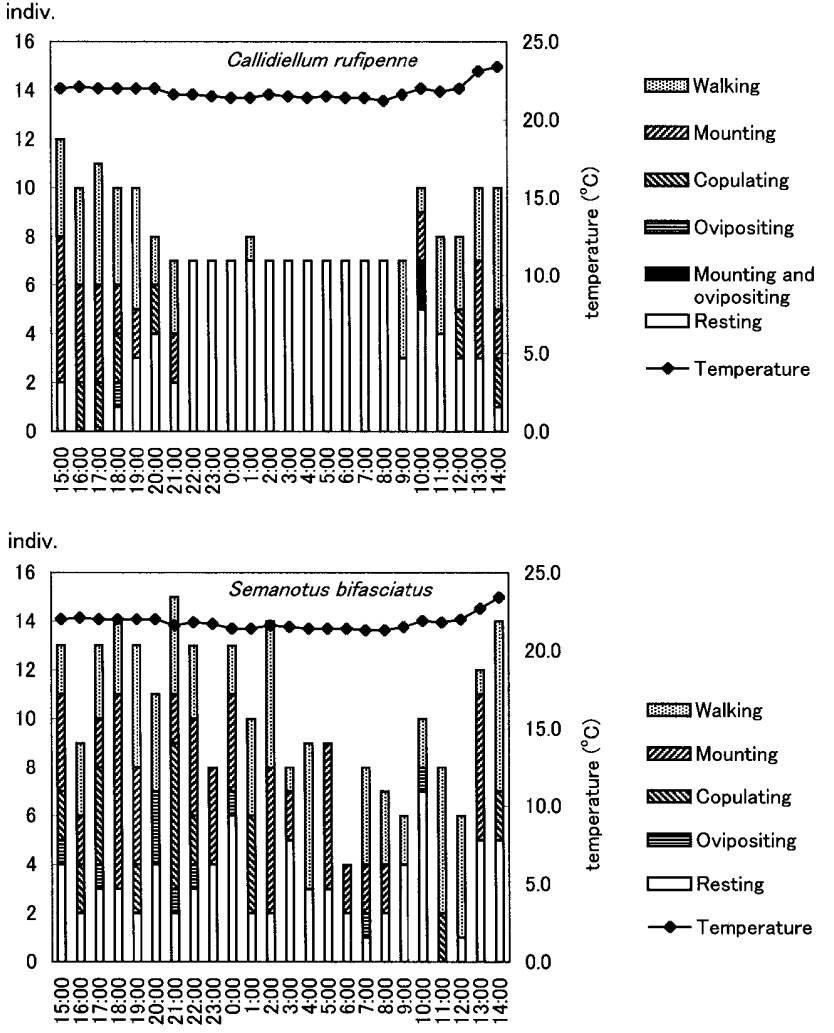

Fig. 1. Daily trends in the activities of adult C. rufipenne and $S$. bifasciatus. Observations were recorded every hour between 15:00, May 20 and 14:00, May 21.

\section{Size and position of larval galleries and entrance holes}

Distribution of larval entrance holes of the two species were concentrated in certain areas on the logs. The mean crowding values (Lloyd, 1967), in which the surfaces (lower, right side, top, left side) are treated as quadrats, are 11.6 for the two species collectively, 5.6 for $S$. bifasciatus and 2.4 for $C$. rufipenne, which indicate that $S$. bifasciatus shows a preference for a particular surface. Then, all the larval entrance holes were categorized as in either the top or lower surface to check whether the two species showed a preference for either surface. The result indicates that there was no significant preference (Fisher's exact probability test; $p=0.49$ ).

Larval gallery area of C. rufipenne was $4.95 \mathrm{~cm}^{2} /$ beetle, whereas that of $S$. bifasciatus was $8.52 \mathrm{~cm}^{2} /$ beetle, indicating that the latter species eats about 1.7 times as much as the former species. This is consistent with the fact that adults of $S$. bifasciatus are larger than those of C. rufipenne.

Results of the measurement of larval entrance hole sizes and pupal chamber depths on the upper, side and lower surfaces of the log are shown in Table 2. The major axis of the ellipse of entrance hole opening of $S$. bifasciatus (av. $5.3 \mathrm{~mm}$ ) is significantly larger than that of $C$. rufipenne (av. $3.3 \mathrm{~mm}$ ) (MannWhitney $U$ test, $|z|=4.03, p<0.001)$. Also, the pupal chamber of $S$. bifasciatus (av. $28.9 \mathrm{~mm}$ ) is significantly deeper than that of $C$. rufipenne (av. $14.7 \mathrm{~mm})(U=10, p<0.05)$. These are again consistent with the difference in size of the two species.

If it is assumed that the size of larval entrance hole is correlated with beetle size, as in Monochamus alternatus Hope (Lamiinae) (Iwata et al., unpubl.), then the results indicate that C. rufipenne larvae grow larger when they develop in the upper surface, whereas $S$. bifasciatus larvae grow larger when in the lower surface. The difference in distribution is assumed to correspond to difference in moisture content in the log.

On the other hand, the depth of the pupal chamber appears not to be associated with beetle size; this parameter seems to be species-specific and probably associated with environmental conditions, including moisture.

As stated by Hori (1970), the positions of the entrance holes differed in the two species: in C. rufipenne, they are located at the end of the gallery, whereas in S. bifasciatus, they are located slightly off the end of the gallery, indicating a slight retrogression, as in S. japonica (Lacordaire) (Minagawa, 1938; Fujishita \& Okada, 1968). These may be characteristic of the genera.

Hayakawa \& Hori (1971) reported that the lower surface of Ch. obtusa logs, lying on the ground, is more favourable for the occurrence and development of $S$. bifasciatus than the top surface. They ascribed this to the lower loss of heat and moisture from the lower than the top surface of logs. The results of our laboratory rearing verified that $S$. bifasciatus occurs mainly in the lower surface and that this can only be ascribed to variation in moisture content since the experiment was carried out in the laboratory, where other environmental factors varied little.

TABLE 2. Sizes of larval entrance holes and depths of pupal chambers (av. \pm S.D.) of Semanotus bifasciatus and Callidiellum rufipenne in different positions on a Thujopsis dolabrata log.

\begin{tabular}{|c|c|c|c|c|}
\hline \multirow{2}{*}{ Species } & & \multicolumn{3}{|c|}{ Position on the log } \\
\hline & & upper & side & bottom \\
\hline \multirow{4}{*}{ S. bifasciatus } & $n$ & 4 & 4 & 8 \\
\hline & $\begin{array}{l}\text { Major axis of elliptic } \\
\text { entrance holes (mm) }\end{array}$ & $4.50 \pm 0.77$ & $5.28 \pm 1.19$ & $5.62 \pm 0.85$ \\
\hline & $\begin{array}{l}\text { Minor axis of elliptic } \\
\text { entrance holes (mm) }\end{array}$ & $2.85 \pm 0.76$ & $3.25 \pm 0.82$ & $3.55 \pm 0.64$ \\
\hline & $\begin{array}{l}\text { Depth of pupal } \\
\text { chambers (mm) }\end{array}$ & $20.1 \pm 5.1$ & $26.0 \pm 5.9$ & $34.8 \pm 7.1$ \\
\hline \multirow{4}{*}{ C. rufipenne } & $n$ & 2 & 3 & 5 \\
\hline & $\begin{array}{l}\text { Major axis of elliptic } \\
\text { entrance holes (mm) }\end{array}$ & $3.50 \pm 0.40$ & $3.75 \pm 0.40$ & $3.02 \pm 0.30$ \\
\hline & $\begin{array}{l}\text { Minor axis of elliptic } \\
\text { entrance holes (mm) }\end{array}$ & $2.30 \pm 0.10$ & $2.03 \pm 0.53$ & $1.92 \pm 0.29$ \\
\hline & $\begin{array}{l}\text { Depth of pupal } \\
\text { chambers (mm) }\end{array}$ & $15.8 \pm 4.5$ & $15.9 \pm 5.0$ & $13.4 \pm 2.3$ \\
\hline
\end{tabular}



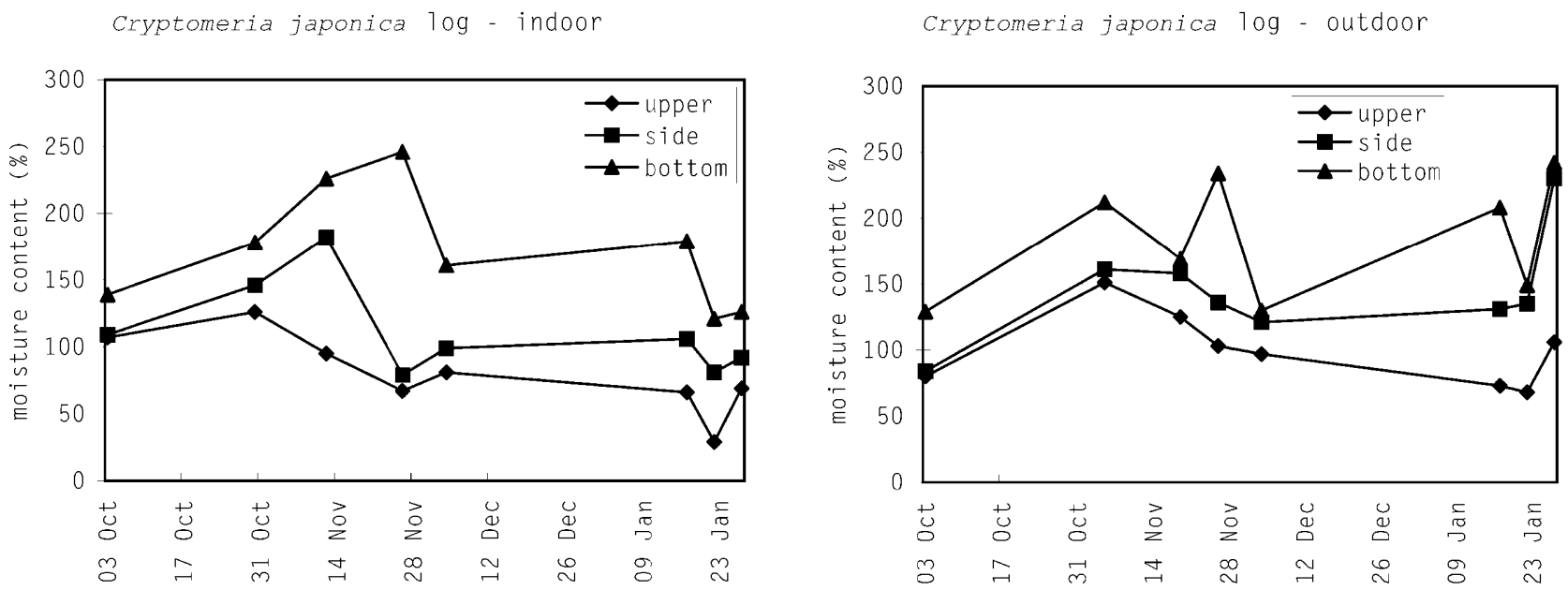

Chamaecyparis obtusa log - indoor

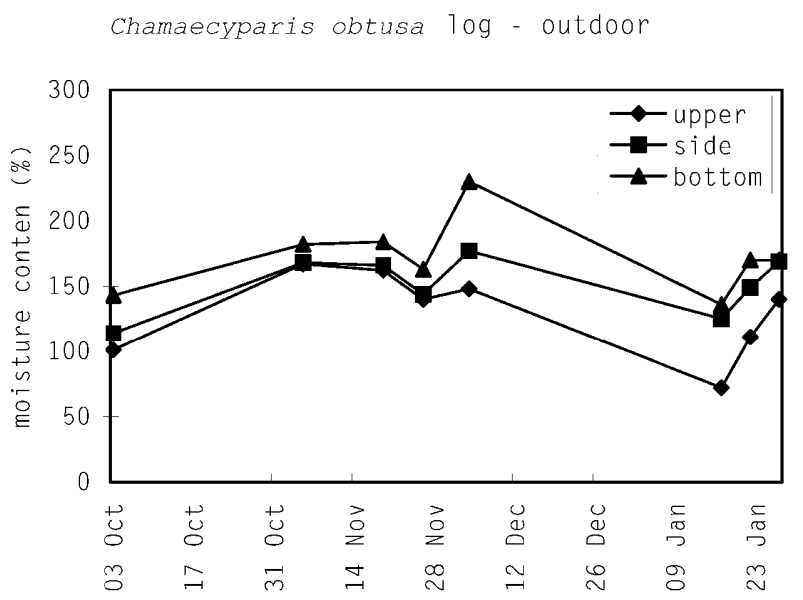

Fig. 2. Trend in the moisture contents of Cr. japonica and Ch. obtusa logs laid horizontally in the laboratory and the field.

\section{Variations in the moisture content of the wood of horizontal $\operatorname{logs}$}

Since the larvae of C. rufipenne developed best in the upper surface and those of $S$. bifasciatus in the lower surface of logs, and this was ascribed to a difference in the moisture content of the wood, further experiments were conducted to evaluate the spatial/temporal variation in the moisture content of horizontal logs of Cr. japonica and Ch. obtusa. For both types of logs in both outdoor and indoor conditions, the moisture content of the lower surface was always the highest, followed by the sides and at the upper surface the lowest (Friedman's test, $p<0.001$; Fig. 2 ). This distribution is ascribed to gravity causing the water to move downwards and variation in evaporation due to the different exposure to shade/sunny conditions, although Fisher et al. (1953) mentioned only the latter. The physical factors that mainly determined the distribution of subcortical insects in logs are moisture content and temperature (Graham, 1924, 1925; Hanks et al., 1999). Of these, fluctuation and variation in temperature were thought to be slight in the indoor laboratory condition, yet a variation in the moisture content of the top (dry) and lower (moist) parts of the log was clearly apparent (Fig. 2). The result of laboratory rearing, together with those of log moisture content experiments, indicate that the preference of $S$. bifasciatus and C. rufipenne for the lower and top surfaces of horizontal logs, respectively, are associated with the moisture content of the wood.
As well as the congeneric Callidiellum villosum (Fairmaire) from China, C. rufipenne is known to be a drywood borer in Japan, preferring dry logs, and because of its tolerance of dryness can be transported abroad in timber, as stated by Iwata et al. (2006). This is consistent with the results presented here. It is concluded that $S$. bifasciatus and $C$. rufipenne can coexist in coniferous logs, and their coexistence can be ascribed to two segregation factors: adult segregation based on temperature and sunshine preferences and larval segregation based on wood moisture content.

ACKNOWLEDGEMENTS. We thank E. Shibata (Nagoya University) for his critical reading of the manuscript. We also thank F. Yamada for his kind supervision and encouragement throughout this study. T. Usui and K. Yajima helped us determine the moisture contents of Cr. japonica and Ch. obtusa logs.

\section{REFERENCES}

BEAVER R.A. 1984: Insect exploitation of ephemeral habitats. Sth Pac. J. Nat. Sci. 6: 3-47.

Fisher R.C., Thompson G.H. \& WebB W.E. 1953: Ambrosia beetles in forest and sawmill: Their biology, economic importance and control. Part I: Biology and economic importance. For. Abstr. 14: 381-389.

Funishita A. \& OKada T. 1968: [Effects of attacking forms by larvae of Sugi bark borer on growth of trees, Semanotus japonicus Lacordaire (Cerambycidae, Col.)]. Kenkŷu-Hôkoku, 
Hiroshima-ken-ritsu Ringyô-Shikenjô, Kabe 3: 104-109 [in Japanese with English title].

Graham S.A. 1924: Temperature as a limiting factor in the life of subcortical insects. J. Econ. Entomol. 17: 377-383.

Graham S.A. 1925: The felled tree trunk as an ecological unit. Ecology 6: 397-411.

Hanks L.M., Paine T.D., Millar J.G., Campbell C.D. \& Schuch U.K. 1999: Water relations of host trees and resistance to the phloem-boring beetle Phoracantha semipunctata F. (Coleoptera: Cerambycidae). Oecologia 119: 400-407.

Hayakawa H. \& Hori K. 1971: [Food habit and bionomics of cerambycid larvae in Nagano Prefecture. Notes on cerambycids of Nagano Prefecture 3.] Annu. Rep. Matsumoto Entomol. Soc. (Matsumoto) 8: 68-96 [in Japanese].

Hellrigl K.G. 1971: Die Bionomie der europäischen Monochamus-Arten (Coleopt., Cerambycid.) und ihre Bedeutung für die Forst- und Holzwirtschaft. Redia (Ser. 3) 52: $367-509$.

HoRI K. 1970: Morphology and ecology of a longicorn beetle, Semanotus bifasciatus Motschulsky (Coleoptera, Cerambycidae). (Notes on longicorn beetles from Nagano Prefecture, Japan 2.) New Entomol. (Matsumoto) 19: 11-19 [in Japanese with English abstr.].

Iwata R., Kawakami Y. \& Nisato T. 2006: [Occurrence of Callidiellum villosum villosum (Fairmaire) (Coleoptera: Cerambycidae) from an imitation christmas tree manufactured in China.] House and Household Insect Pests 28: 85-89 [in Japanese with English abstr.].

KoвауASHi K. 1984: [Effects of temperature on the diapuse and emergence of Semanotus japonicus and Palaeocallidium rufipenne (Coleoptera: Cerambycidae).] Transactions of the 95th Annual Meeting of the Japanese Forestry Society. pp. 491-492 [in Japanese with English title].

Kojma K. \& Nakamura S. 1986: [Food Plants of Cerambycid Beetles (Cerambycidae, Coleoptera) in Japan.] Hiba Society of Natural History, Shôbara, $12+336$ pp. [in Japanese with English title].

Kollmann F.F.P. \& CôTÉ W.A. JR. 1968: Principles of Wood Science and Technology. I. Solid Wood. Springer-Verlag, Berlin/Heidelberg, $12+592$ pp.

Lloyd M. 1967: "Mean crowding”. J. Anim. Ecol. 36: 1-30.

MinagaWA M. 1938: [On the larval morphology and bionomics of Semanotus japonicus and Callidium rufipenne (Coleoptera: Cerambycidae).] Ôyo-Dôbutsugaku-Zasshi, Tokyo 10: 53-68 [in Japanese].
NiISATO T. 1992: [Tribe Callidiini Mulsant, 1839.] In Ohbayashi N., Satô M. \& Kojima K. (eds): An Illustrated Guide to Identification of Longicorn Beetles of Japan. Tokai University Press, Tokyo, pp. 134-135, 507-511 [in Japanese with English title].

Paine T.D., BIRCh M.C. \& Švihra P. 1981: Niche breadth and resource partitioning by four sympatric species. Oecologia 48: $1-6$.

RANKIN L.J. \& Borden J.H. 1991: Competitive interactions between the mountain pine beetle and the pine engraver in lodgepole pine. Can. J. Forest Res. 21: 1029-1036.

ShiBata E. 1994: Population studies of Callidiellum rufipenne (Coleoptera: Cerambycidae) on Japanese cedar logs. Ann. Entomol. Soc. Am. 87: 836-841.

STARZYK J.R. 1968: The daily activity rhythm of Gaurotes virginea (L.) (Coleoptera, Cerambycidae). Folia Biol. 16: 267-282.

Sugiyama T., Urano H., Itino T., IchiKawa T. \& Okamoto H. 1991: [Behavior of the sugi bark borer, Semanotus japonicus (Coleoptera: Cerambycidae), on live standing trees of Japanese cedar in a wood.] Jap. J. Entomol. 59: 675-691 [in Japanese with English abstr.].

Sugiyama T., Anami H., Ichino T., Ichikawa T. \& OKamoto H. 1992: [The flights of adults of the sugi bark borer, Semanotus japonicus (Coleoptera: Cerambycidae), from standing trees of Japanese cedar and their behaviors on branches and on the ground.] J. Jap. For. Soc. 74: 273-281 [in Japanese with English abstr.].

Wickman B.E. 1968: The biology of the fir tree borer, Semanotus litigiosus (Coleoptera: Cerambycidae), in California. Can. Entomol. 100: 208-220.

WU W.-W. \& JIANG S.-N. 1986: [Discrimination of Semanotus bifasciatus bifasciatus (Motschulsky) and S. bifasciatus sinoauster Gressitt (Coleoptera: Cerambycidae), and the investigation on their taxomomic stati.] Sci. Silv. Sin. 22: 147-151 [in Chinese].

Yogo S. 1954: [Host plant selection of Semanotus rufipennis Mots. for oviposition.] Transactions of the 63rd Annual Meeting of the Japanese Forestry Society. pp. 218-220 [in Japanese with English abstr.].

Zhang L.-Q., WANG S.-F. \& Shao L.-C. 1983: [Semanotus bifasciatus sinoauster (Cerambycidae)]. In Academia Silvae Sinicae (ed.): Forest Insects of China. Zhongguo Linye Chubanshe, Beijing, pp. 298-302 [in Chinese].

Received July 19, 2006; revised and accepted December 18, 2006 